\title{
Multi-Drug Resistant, Extended Spectrum beta- Lactamase and Carbapenemase Producing Bacterial Isolates among Septicemia Suspected under Five Children in Tikur Anbesa Specialized Hospital, Addis Ababa Ethiopia: Cross-sectional study
}

Mequanint Mitiku

Black Lion Hospital

Zeleke Ayenew ( $\sim$ zelekeayenew377@gmail.com )

https://orcid.org/0000-0003-4216-6634

Kassu Desta

Addis Ababa University School of Medicine

Research article

Keywords: Blood stream infection, BacT/Alert, multi-drug resistance, Extended spectrum beta-lactamase, Carbapenem resistance entrobacteriaciae.

Posted Date: August 14th, 2019

DOI: https://doi.org/10.21203/rs.2.12864/v1

License: (c) (i) This work is licensed under a Creative Commons Attribution 4.0 International License. Read Full License 


\section{Abstract}

Background: Bloodstream infections due to bacterial pathogens are a major cause of morbidity and mortality among pediatric patients. Emergence of drug resistance in high classes of antibiotics among the bacterial pathogens is another issue of the public health concern. Therefore this study aimed to determine Multi-drug resistant, extended spectrum $\beta$-lactamase and carbapenemase producing bacterial isolates among septicemia suspected under five Children in Tikur Anbesa Specialized Hospital, Addis Ababa Ethiopia. Methods: Acrosssectional study was conducted from September 2017 to June 2018 among pediatric patients with febrile illness aged under five in Tikur Anbesa Specialized Hospital. Three hundred forty blood samples were collected and processed following standard microbiological techniques and culture was performed using BacT/Alert machine in combination with conventional method. AST of the isolates was performed by Kirby-Bauer disc diffusion method and MIC technique Result: A total of 137(40.2\%) bacterial pathogens were isolated from 340 pediatric patients suspected of BSI with febrile illness. Of these isolates $54 \%$ were Gram negative bacteria. Of the isolates $43(31.4 \%)$ Klebsiella pneumoniae and Acinitiobactor species were the most frequently isolated pathogens. Klebsiella pneumoniae isolates were 95.6\% MDR, 23.7\% ESBL, and 27.1\% CRE in children. Conclusion: In this study, Klebsiella pneumoniae and S. aureus are common pathogens associated with BSI in pediatrics with high antimicrobial resistance. The prevalence of MDR 51.1\%, CRE 30.5\% and ESBL 25.4\% were alarmingly high in bacterial isolates. ESBL producing organisms were common in Klebsiella species and Escherichia coli isolates. Since most of isolates exhibit multidrug resistant, invitro- susceptibility of antimicrobials is mandatory. Strengthen antimicrobial surveillance system and antimicrobial stewardship are necessary for better management of antibiotics in addition to infection prevention practice in TASH settings. Key words: Blood stream infection, BacT/Alert, multi-drug resistance, Extended spectrum beta-lactamase, Carbapenem resistance entrobacteriaciae.

\section{Background}

Blood circulatory system infection stays one of the most significant reasons for horribleness and mortality all through the world. Roughly 200,000 instances of bacteremia happen every year with death rates running from 20 -half overall [1]. Blood circulatory system infection represents $10-20 \%$ of every single nosocomial disease and is the eighth driving reason for mortality, in the United States some $17 \%$ of result in death [2]. In sub Saharan nations including Ethiopia septicemia is a significant reason for sickness and passing in youngsters, the death rate approaches $53 \%$ which makes it a noteworthy medical issue in under developed countries [3].

In numerous investigations a wide scope of microscopic organisms has been portrayed in febrile patients including gram negative microorganisms, for example, Escherichia coli, Pseudomonas aeruginosa, Klebsiella species, Neisseria meningitidis, Haemophilus influenzae, and gram positive, for example, Coagulase negative staphylococci (CONS), Staphylococcus aureus, Streptococcus pneumoniae, Streptococcus pyogenes, Streptococcus agalactiae, and Enterococcus faecium [4]. The determination of these microorganisms can be affirmed by blood culture, which is routinely accessible in couple of Hospitals in developing nations [5].

Bacterial pathogens isolated from blood stream infection are a main source of critical patient morbidity and mortality. The effect of explicit etiologic specialists on BSI persistent result are enormous; BSI builds the death rate, drags outpatient remain in an emergency unit in the Hospital, and prompts expanded human services costs $[6,7]$. 
The auspicious and suitable utilization of anti-microbial is as of now the best way to treat bacteremia. In any case, numerous bacterial pathogens have turned out to be impervious to anti-infection regimens and become a genuine general wellbeing worry with financial and social ramifications all through the world. Anti-microbial resistance is a developing issue in developing nations, for example, Ethiopia. In Ethiopia the unregulated overthe-counter closeout of these antimicrobials, for the most part for self-treatment of suspected disease in people, and to a lesser degree for use in creatures without remedy, would unavoidably prompt rise and quick dispersal of obstruction [8]. Numerous examinations have discovered that lacking experimental treatment of bacteraemic infection is related with antagonistic results, including expanded mortality and expanded medication obstruction development [9-10].

During the previous couple of decades, antimicrobial opposition has expanded around the world, and the points of view are disturbing [11]. The nature, the greatness and approaches to adapt to this issue are contemplated and depicted in the western world, while this base of learning is deficient in creating African nations [12-14].

We lack reports on mortality related to distribution of pathogens and their resistance patterns. Without such reports, guidelines for empiric treatment of severe bacterial diseases cannot be given. While updated studies on outcome in sepsis in Africa are almost non-existent, there are a few reports on bacterial culture results. The most alarming reports on antimicrobial resistance concern patients admitted to Hospitals [15], while communityacquired infections may have lower profiles of resistance [16]. In Ethiopia, the resource situation has not allowed antimicrobial resistance to be prioritized as major public health concern despite the obvious needs [17]. The aim of this study was to identify and determine Multi-drug resistant, extended spectrum $\beta$-lactamase and carbapenemase producing bacterial isolates among blood culture samples from under five patients attending to Tikur Anbesa Specialized Hospital by automated BacT/Alert machine.

\section{Methods}

\section{Study setting}

The study was conducted in Tikur Anbesa Specialized Hospital (TASH), the teaching Hospital of health Science College, Addis Ababa University. TASH is the largest specialized Hospital in Ethiopia, with over 700 beds, and serves as a training center for undergraduate and postgraduate medical students, dentists, nurses, midwives, pharmacists, medical laboratory technologists, radiology technologists, and others who shoulder the health

problems of the community and the country at large. With more than 70 percent of childhood deaths attributable to communicable diseases and malnutrition, Ethiopia's healthcare resources have been directed primarily to treat and prevent diseases such as malaria and diarrhea [18].

\section{Study design and period}

A cross-sectional study was conducted from September 2017 to June 2018 to identify the bacterial profiles and antimicrobial susceptibility pattern among septicemia under five patients with acute febrile illness in Tikur Anbesa Specialized Hospital in Addis Ababa.

\section{Inclusion and Exclusion criteria}


Children aged under five years including neonates with fever and those who are diagnosed with sepsis, Sever sepsis and septic shock. In addition, all children who gave blood sample and their parents volunteer to give permission to participate on the study. However those participants clinically none febrile patients under five years. Patients who took antibiotics currently within the last 7 days were excluded.

\section{Sample size calculation}

The sample size for the study that infers the total population was determined using a single population proportion formula. The study considered the previous study of prevalence and antibiotic resistance of bacterial pathogens isolated from children under five in septicemia patients at Tikur Anbesa Specialized Hospital 27.9\% bacterial isolation (19), at $95 \%$ level of confidence and $5 \%$ margin of error. $n=(Z a)^{2}(p q) / d^{2}$ Where: $n=$ sample size $\mathrm{Za} / 2$ = level of confidence $\mathrm{P}=$ diarrhea prevalence $\mathrm{q}=1-\mathrm{p} d 2=$ margin of error $(0.05): \mathrm{n}=\underline{\mathrm{z}^{2} *} \underline{\mathrm{p}}$ * $\mathrm{q} /$ $d^{2}$

$, p=0.279, q=0.721, d=0.05, Z a / 2=1.96 ; \underline{1.96} \underline{2} * 0.279 * 0.721 / 0.05^{2}=309$. Considering $10 \%$ non- response rate, the totals of 340 children patients were enrolled in the study.

\section{Sampling technique}

The study subjects were selected using convenient sampling technique from all patients attending Tikur Anbesa specialized Hospital among under five children with febrile illness clinically diagnosed at pediatric OPD, ICU and impatient pediatric ward admitted during the study period. Sampling technique was employed for those children fulfill the inclusion criteria.

\section{Data collection procedure}

Well standardized questionnaire was used to collect socio-demographic characteristics (sex, age, clinical presentation (fever, vomiting and household income). Patients visiting outpatient departments (pediatric and general medicine) and those admitted in the inpatient units were investigated for bloodstream infections by respective unit physicians. At the onset of fever $(>37 \circ \mathrm{C})$ or in the presence of any clinical symptoms compatible with infection.

\section{Blood sample collection}

A venous blood culture specimen was taken with aseptic technique by cleansing of the collection site with $70 \%$ alcohol and subsequently followed by $10 \%$ povidone-iodine solution by trained laboratory personnel. About $2.5-$ $5 \mathrm{ml}$ of blood specimen was collected and inoculated into aerobic 30ml BacT/ALERT PF Plus pediatric bottles at the blood to broth ratio of 1: 10-1:30. At least 2 sets of blood cultures were collected from a patient with suspected bacteremia prior to the initiation of antimicrobial therapy.

\section{Culture Isolation and Identification}

Venous blood to BacT/ALERT culture bottles were incubated in automatic BacT/ALERT ${ }^{8} 3 D$ at 37 oC of $5 \%$ $\mathrm{CO} 2$ for 5 days for the primary isolation of the microorganism. Two aerobic blood culture bottles were used for each patient and growth in both bottles were considered positive. The microbial growth that could be detected by flag and audible sound of the instrument will subsequently be sub culture on $5 \%$ sheep blood Agar, chocolate, 
and MacConkey Agar plate (Oxoid Ltd, UK) and incubate at 37oC for 18-24 for bacterial isolation. The MacConkey agar plate was incubated aerobically while chocolate and blood agar were incubated in microaerophilic atmosphere (5-10\% C02) candle Jar. A negative result was checked by examining the flag and doing gram stain and a final subculture at the end of 5 th day prior to discarding as negative. The significant growth colonies were examined morphologically for size, consistency, shape, hemolytic and ability to ferment lactose. For gram negative bacteria convectional biochemical test was performed [20].

\section{Antibiotic Susceptibility Test}

Pure Colony of isolated bacterial organism was mixed with $0.85 \%$ normal saline and measured at $0.5 \mathrm{McF}$ arland standards for susceptibility testing. The bacterial isolates were tested against the following drugs commonly

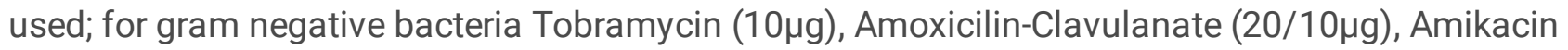

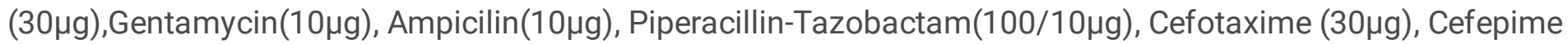
$(30 \mu \mathrm{g})$, Ceftriaxone $(30 \mu \mathrm{g})$, Ciprofloxacin $(5 \mu \mathrm{g})$, Impenem/ Meropinem (10 $\mu \mathrm{g})$, Trimethoprim- Sulfamethoxazole $(1.25 / 23.75 \mu \mathrm{g})$, Nalidixic Acid $(30 \mu \mathrm{g})$ were tested. Kirby-Bauer's Disk Diffusion method was used for susceptibility of the isolates on Muller Hinton agar was referred to the standard interpretative chart reporting the zone sizes of each antimicrobial in CLIS guidelines [21].

\section{Detection of Carbapenem Resistance}

All the Carbapenem (imipenem or Meropenem) resistant or intermediate isolates were checked for the presence of carbapenemase using modified Hodges test (MHT), also known as the clover leaf test as per the CLSI. Presence of indentation indicates a positive test and the isolate was a carbapenemase producing strain. No growth of the ATCC E. coli 25922 along the organism growth streak indicates a negative test and the isolate is not a carbapenemase producer.

\section{Detection of Extended spectrum beta-lactamase}

Initial screening for ESBL was done by the diameters of zones of inhibition produced by Ceftazidime (30 $\mathrm{gg})$, Ceftriaxone $(30 \mu \mathrm{g})$ and Cefotaxime $(30 \mu \mathrm{g})$ found to be within the CLSI screening criteria. These breakpoints indicative of thought for ESBL production are: for CAZ $\leq 22 \mathrm{~mm}, \mathrm{CRO}, \leq 25 \mathrm{~mm}$ and for CTX $\leq 27 \mathrm{~mm}$. Phenotypic detection of ESBL production was confirmed by double disk synergy test and combined disk test according to CLSI(2017) guideline.

\section{Combined disk (double disk potentiate) Test (CDT)}

A Ceftazidime $(30 \mu \mathrm{g})$ disk and Cefotaxime $(30 \mu \mathrm{g})$ dick were used alone and their combination with Clavulanic acid $(30 \mu \mathrm{g} / 10 \mu \mathrm{g})$ for phenotypic confirmation of the presence of ESBLs. A $\geq 5 \mathrm{~mm}$ increase in zone diameter for either of the Cephalosporin disks and their respective Cephalosporin/Clavulanate disk were interpreted as ESBL producer. This method (according to CLSI) is used as reference phenotypic method for comparing double disk synergy method.

\section{Double Disk Synergy Test (DDST)}

The organism to be tested was spread onto a Mueller-Hinton agar plate. The antibiotic disks used are Ceftriaxone $(30 \mu \mathrm{g})$, Cefotaxime $(30 \mu \mathrm{g})$, Ceftazidime $(30 \mu \mathrm{g})$, Aztreonam $(30 \mu \mathrm{g})$ and Amoxicillin/ Clavulanic acid 
$(20 / 10 \mu \mathrm{g})$. The four antibiotics were placed at distances of $20 \mathrm{~mm}$ (edge to edge) from the Amoxicillin/Clavulanic acid disk placed in the middle of the plate. After 24-h incubation, if an enhanced zone of inhibition between either of the cephalosporin antibiotics and the Amoxicillin/Clavulanic acid disk occurred, the test was considered positive.

\section{Data Quality assurances}

Media preparation as per manufacturer instructions and laboratory Standard Operating Procedures (SOP) was strictly followed. Verify that media meet expiration date and quality control parameters per CLSI. Labeling container, media, filling the forms were carried out.

Visual inspections of cracks in media or plastic petri-dishes, unequal fill, hemolysis, evidence of freezing, bubbles, and contamination were performed. Use ATCC control strain for each isolated bacterium including E. coli 25922, S. aureus 25923, Pseudomonas areuginosa 27853, H.influnzae 10479. Report the results on log sheet and stored for further data. Samples were stored at $-80 \mathrm{cc}$ in skim milk.

\section{Data analysis and interpretation}

SPSS versions 20.0 was employed to analyze the work and to make inferences on the frequency of occurrence of the bacterial pathogens associated with febrile illness and to show the resistance pattern to antibiotic substances. Descriptive statistics to analysis by using frequency, proportions graphs, crosstabs and odds ratio. Bivariate analysis was performed for each factors associated with blood stream infection. Regression analysis was conducted to identify associated factors and how they are associated with dependent variables. The strength of association was presented by odds ratio and 95\% confidence interval and p-value of $<0.05$ was considered as statistical significant association.

\section{Dissemination and Utilization of Results}

After the completion of the study the research were disseminated to Department of Medical Laboratory Sciences, School of Allied Health Science, College of Health Science, and Addis Ababa University. It will also be submitted for scientific publication.

\section{Operational Definitions}

Antimicrobial resistance: occurs when microorganisms change in ways that render the medications used to cure the infections they cause ineffective.

Extended spectrum $\beta$-lactamase (ESBL): Extended-spectrum beta-lactamases (ESBL) are enzymes that confer resistance to most beta-lactam antibiotics, including penicillins, cephalosporins, and the monobactamaztreonam.

Multidrug resistance (MDR): is antimicrobial resistance shown by a species of microorganism at least to one drug in three different classes of antibiotics.

\section{Results}


Among the study participants 122(35.9\%) were males and 218 (64.1\%) were females resulting in an overall female to male ratio of $1.7: 1$. The mean age of pediatrics participated in this study was $1.04 \pm 1.0$ (SD) years.From the study patients 76(22.4\%) were from pediatric OPD and 181(53.2\%), 83(24.4\%) from inpatient ward and ICU ward respectively. The proportion of culture positive patients in the ICU 59/83(71.1\%), impatient 66/181(36.5\%) and pediatric OPD 10/76 (13.2\%) patients were identified (Table 1).

\section{Clinical features}

Patients showed different clinical diagnosis before confirmed their BSI in blood culture, most of were sepsis 102(30.0\%) followed by Early onset of neonatal sepsis /EoNS/ 71 (20.9\%),Late onset neonatal Sepsis/LoNS 48(14.1\%) and Hospital acquired infection 43(12.6\%). However, the distribution of positive blood culture among patients with different clinical diagnosed disease type suspected of having BSI showed that among clinical disease in endocarditis 7/11(63.6\%), Hospital acquired infection 26/43(60.5\%), sepsis 49/102 (48\%) and late neonatal sepsis 21/48 (44\%) high positive blood culture were identified as shown (Figure1).

\section{Bacteria pathogens among blood stream infection}

Of 340 paired blood sample bottles, a total of 137(40.2\%) bacterial pathogens were isolated from pediatric patients suspected of BSI with febrile illness. Among positive blood culture results about $54 \%$ of them were Gram negative bacteria with. Klebsiellapneumoniae was the highest incidence $31.4 \%$ followed by Acinitiobactor species (8.7\%). Double infection from pseudomonas species and Klebsiellaoxytoca were identified in one patient as shown (Figure2).

\section{Antimicrobial susceptibility Testing}

Trends of antibiotics prescribed were assessed prior to blood sample collection before 7days and about 148(43.5\%) participants have taken antibiotics empirically, of these 49(33.1\%) were culture positive during the study. Ampicillin and Gentamicin were among the most common empirical prescribed antibiotics. After collection of positive blood culture results about 20 antibiotics were applied in 137(40.2\%) isolates and it revealed that the most prescribed antibiotics cotrimosazole, gentamycin, and ciprofloxacin showed high resistance.

\section{Antimicrobial susceptibility pattern of Gram negative bacterial isolates}

In 74 gram negative isolates with exception of Salmonella species, susceptibilities of beta-lactam antibiotics, fluoroquinolones, aminoglycosides, and carbapenems were applied for isolates from pediatric patients. The predominant gram negative isolates from BSI were Klebsiellapneumoniae species showed resistance to ampicillin (100\%) and cotrimosazole (90.7\%). On the other hand, the isolates susceptible to meropenem (62.8\%) and Piperacillin-Tazobactam (58.1\%). All Acinitobactor species were highly resistance to tested antimicrobials such as cefepime (100\%), ceftazidime (90.9\%), 72.7\% for each meropenem and ciprofloxacin. Pseudomonas 
species also showed fifty percent (50\%) resistance to anti-pseudomonal antibiotics gentamycin, ciprofloxacin, cefepime, Amikacin and ceftazidime but it was susceptible $75 \%$ to meropenem and Piperacillin-Tazobactam. All Salmonella species completely susceptible to Ciprofloxacin, ceftriaxone, and ampicillin and less susceptible to cotrimosazole (50\%) (Table 2).

\section{Multi-drug resistant isolates}

Antibiogram pattern of the isolates in this study showed that multidrug resistance among gram negative isolates the prevalence of multidrug resistance (MDR) in Pseudomonas aeruginosa showed that two (50\%) of the isolates exhibit resistance to three antibiotics. In Klebsiellapneumoniae, majority of isolates $35(81.4 \%)$ were resistance to eight and more tested antibiotics even though 2(4.6\%), 1(2.3\%), 2(4.6\%) and 2(4.6\%) isolates were resistance consecutively to three, four, sixand seven antibiotics respectively. Among eleven Acinitobacter species $7(63.6 \%)$ isolates were resistance to eight and more antimicrobials and $1(9.1 \%)$ was resistance to seven antibiotics the least isolate of gram negative bacteria Entrobacter cloacae 1(100\%) was resistance to eight and more antibiotics. However there was no MDR in Citrobacter and Salmonella species (Table 3).

\section{Carbapenem resistant Enterobacteriaceae (CRE)}

Out of 59 enterobacteriaceae isolates 18 (30.5\%) of them were resistant to Carbapenem (Meropenem) by producing KPC and 41 (69.5\%) were sensitive. The predominate carbapenem resistance enterobacteriaceae species in our study were Klebsiellapneumoniae $27.1 \%(n=16 / 59)$ followed by Klebsiellaoxytoca $3.4 \%(n=2 / 59)$. More ever, other gram negative non- enterobacteriaceae isolates capable of developing carbapenem resistance were identified in Acinitobactor species 12.2\% $(n=9 / 74)$ and Pseudomonas areuginosa $1.3 \%(n=1 / 74)$ of the total gram negative isolates. A Positive Modified Hodge test showed a clover leaf-like indentation of the Escherichia coli 25922 strain growing along the test organism growth streak within the disk diffusion zone indicating production of carbapenemase.

\section{Extended spectrum beta-lactamase producing enterobacteriaceae}

Screening a total of 74 gram negative bacteria 59(79.7\%) enterobacteriaceae isolates were suspected of ESBL producing organisms. Klebsiellapneumoniae $27.1 \%(n=16 / 59)$ and Escherichia coli $1.7 \%(n=1 / 59)$ were among gram negative enterobacteriaceae isolates showing ESBL producers.

Combined disk (double disk potentiate) Test (CDT): The overall prevalence of ESBL producing enterobacteriaceae was $28.8 \%(n=17 / 59)$. Among the suspected 17 isolates $100 \%(n=17 / 17)$ were phenotypically confirmed for ESBL using combination disk method, K. pneumoniae $100 \%(n=16 / 16)$ and E. coli $100 \%(n=1 / 1)$ were positive for ESBL (figure). For result interpretation we use this result as the CLSI recommend this technique as reference for other phenotypic methods. We also use this test result to compare the findings of double disk method.

Double Disk Synergy Test (DDST): All isolates $(n=17)$ were further tested for ESBL production by double disk synergy procedure, another phenotypic confirmatory method. The double disk Synergy method indicated $82.3 \%$ $(n=14 / 17)$ were confirmed for ESBL producing enterobacteriaceae. Thus, K. pneumoniae showed from the $100 \%$ $(n=17 / 17)$ which were positive by the reference (CDT) method, $82.3 \%(n=14 / 17)$ were positive by this method 
while $17.6 \%(n=3 / 17)$ were negative. However E. coli 100\% $(n=1 / 1)$ was ESBL positive concordant done by two methods.

\section{Discussion}

Blood stream infection (BSI) in pediatric patients associated with febrile illness is a major public health problem especially in developing countries where high child morbidity and mortality rate. So timely detection of bacteremia in blood culture set is a promising diagnostic tool established to rule out bacteremia and determination of its antimicrobial Susceptibility profile is necessary for clinicians to decide appropriate empirical therapy, which ultimately decreases the emergence of drug resistance [22]. The present study included 340 pediatric patients under five years of age clinically diagnosed with different disease suspected of bacteremia. Even though no statistical significant association for Endocarditis (63\%), Hospital acquired infection (60\%) sepsis (48\%) patients were the highest proportion of positive blood culture for bacteremia [Table1].

In this study, overall prevalence of bloodstream infection based on significant bacterial growth in the blood cultures obtained from suspected patients was 137 (40.2\%) which was in agreement for studies prevalence range of 35\%-45\%, with the study done in Gondar, northern Ethiopia 39.5\% [23] and other similar studies conducted in African countries such as in Egypt 40.7\% [24] and Tanzania 38.9\% [25] and also in India by Zakariya et al.,41.6\% [26] and Khanal et al., [27] has reported 44\% of positive blood cultures. Meanwhile, the present study was higher than the studies conducted in Addis Ababa, Ethiopia 13.0\% [28], 27.9\% [23], and other African counties such as Tanzania 7.7\% [29] and Ghana 19.9\% [30]. The difference between studies might be due to differences patient condition in which our study includes more patients from ICU and impatient than outpatients in addition blood culture was performed by using more sensitive automated BacT/ALERT system. However we have isolated bacteria lower than the studies in Nigeria 47.6\% [31], this was due to the patient condition in which others only include impatient and isolate anaerobic bacteria.

Among the total isolates $54 \%$ gram negative bacteria were causing blood stream infection in children which is in line with the previous study done in Addis Ababa, Ethiopia 51.8\% [23] elsewhere in India 51.8\% [32] Kabul, Afghanistan 51.7\%[33] and in Nepal 55.2\%, 56\%[34] respectively but higher compared to the study done in USA by Larru., et al., 22\%[35] and in South Africa by Crichton et al., 40.7\% [36], this was due to difference in socioeconomic, geographical and infection control mechanisms.

In this study, the most common causes of bloodstream infections were gram-negative bacteria, in particular Klebsiellapneumoniae 31.4 \% followed by Acinitobacter species $8.7 \%$ were the predominate among GNB isolates. This was supported by the study done in Jimma Ethiopia 31.4\% [37],in African countries in Kenya 13\% [38], Ghana 26\% [39] , Bouaké, central Côte d'Ivoire 22.5\%[40] in Asian such as in India by 25.8\%,30.5\%[41,42] in Brazil, Latin America by Berezina et al [43], veitnam 20\% [44] the most common isolate was Klebsiellapneumoniae. However it was inconsistent that the predominant GNB isolation rate varies from country to country where in India by Kante et al., [45], Indonesia by Murni et al., [46] frequently isolated pathogen in BSI was Pseudomonas other than Klebsiellapneumoniae in the same age group. The possible difference might be due the difference prescription of antibiotics for empirical treatment of patients before blood culture and difference of management in pathogens causing nosocomial infection across the counties in addition in our Hospital setting, nosocomial infections were not proper patient isolation system in the ward which further increase the survival of high drug resistant bacteria including Klebsiellapneumoniae. 
A polymicrobial infection in our study was isolated in a single patient and etiologies both were from gram negative bacteria that tends to increase the severity of the diseases which is in agreement with previous study even though some microbiologists consider polymicrobial growth as a contamination, but sepsis should be clinically correlated [47].

The trend of empirical treatment in our study $43.5 \%$ and the most prescribed antibiotics were ampicillin, gentamicin, ciprofloxacin and third -generation cephalosporin (most common ceftriaxone) in which ampicillin and gentamicin were the most common combined drugs used. This was supported by the previous study in Tamale, Ghana [48].

The antimicrobial susceptibility of gram negative bacteria predominately Klebsiellapneumoniae isolates were high level of resistance to ampicillin(100\%), cotrimosazole (90.7\%) and gentamycin (88.4\%),despite of sensitive to meropenem (62.8\%), Piperacillin-Tazobactam (58.1\%) was consistent with the studies by Zenebe et al [49] reported 100\%resistance to ampicillin and Cotrimosazole, in Bahirdar ,Ethiopia by Hailu et al.,[50] ampicillin $91.4 \%$,cotrimosazole $77.1 \%$ and gentamicin $71 \%$ while in India the resistance of ampicillin, cotrimosazole and gentamycin done by Kumar et al.,[41] were 97\%,88\%,67\% respectively. it was also comparable in Kaneti children Hospital, Nepal by kari et al [51] reported 100\% resistance to ampicillin and least sensitive to Cotrimosazole and Gentamycin. The highest potent drugs $3^{\text {rd }}$ and $4^{\text {th }}$ generation cephalosporin, quinoles and carbapenem antibiotics also showed resistance which is a concern for treatment of BSI in pediatrics with septicemia.

The second most predominant GNB isolates in our study were Acinitobacter species resistance to most tested antimicrobials ceftazidime $100 \%$, cefepime $90.9 \%$ gentamycin $81.8 \%$, torbomycin $81.8 \%$ ciprofloxacin $72.7 \%$, meropenem $72.7 \%$ was comparable with other previous studies where high resistance of Acinitobacterspecies was published $[52,53]$. However our result was high rate of resistance compared to the study conducted in South India by Zakariya et al., [54] in which meropenem 100\% sensitive, while $67 \%$ were sensitive to gentamicin, ceftriaxone, ciprofloxacin, ceftazidime and Amikacin reported. This is the fact that we had relatively many isolates and might be due to inappropriate empirical use of meropenem as the first line treatment since most of isolates are from ICU patients in our Hospital.

The overall prevalence of multidrug resistance isolates MDR in our study was $86.5 \%$ of which most of them were Gram-negative bacteria with a very high resistance to beta-lactam antibiotics. This result is supported by the previous study in Ethiopia [19]. Among Gram negative bacterial isolates, Klebsiella 95.9\% and Acinetobacter72.2\% were dominant species. This was consistent with the study in north India [55].

The present study identified carbapenem resistance enterobacteriaceae (CRE) with the rate of $30.5 \%$ comparable with study conducted in Tanzania 35\% [56]. The most carbapenem resistance was detected in $72.2 \%$ isolates of Acinetobacter spp. and in $62.8 \%$ of Klebsiellapneumoniae. This was inconsistent with the study in north India $64 \%, 92 \%$ [55] respectively.

The prevalence of ESBL-producing Enterobacteriaceae in our study is $25.4 \%$. Among 43 Klebsiellapneumoniae isolates 14(32.5\%) and 5 E.coliisolates 1(20.0\%) ESBL-producers which is in line with the study conducted in south India by Zakariya et al., 32.0\% [54] and in Mali by Sangare et al., 29.4\% [57] ESBL producing Klebsiellapneumoniae. 


\section{Limitation of the study}

Even though our study identifies numerous bacteria pathogens causing BSI in pediatrics under five years, we could not able to isolate other possible pathogens including anaerobic bacteria.

\section{Conclusions}

Blood stream infection in pediatric patients caused by Gram negative organisms with high antibiotic resistance were a treat of children. Among the dominate gram negative isolates Klebsiellapneumoniae and Acinitobactorspecies were multidrug resistant including 3rd and 4th generation cephalosporin, quinolones, aminoglycosides, carbapenem. The prevalence of MDR $86.5 \%$, CRE $30.5 \%$ and ESBL $25.4 \%$ were alarmingly high in gram negative bacterial isolates in this study.

The duration of Hospitalization, history of Hospital acquired infection and complication of clinical suspected septicemia with high grade fever were significantly associated with positive blood culture in pediatric patients.

Based on the findings of this study, we recommend that blood culture should be done for pediatric patients prior to antimicrobial therapy with most sensitive BacT/Alert machine. Clinicians should avoid prescribing last line antibiotics for pediatrics in ICU.

Since Majority of antibiotics even last line antibiotics alarmingly resistance, laboratory based treatment should be routinely done. Isolation of patients confirmed nosocomial infection is mandatory to minimize transmission of resistance gene to others including CRE, MDR and ESBL producing organisms in Hospital admitted patients.

Strengthening of antimicrobial surveillance system and antimicrobial stewardship are necessary for better management of antibiotics in addition to infection prevention practice in the Hospital settings.

\section{Abbreviations}

ATCC-American type of culture collection,BSI-blood stream infection,CLSI-clinical laboratory standard institute, CRE-carbapenem resistance entrobactericeae, ESBL-extended spectrum beta lactamase, GNB - gram negative bacteria, ICU-intensive care unit, MDR - Multi drug resistance.

\section{Declarations}

The author's declare that the study is their original work

\section{Ethics approval and consent to participate}

The study was conducted after it was approved by the department of Medical Laboratory Sciences research and ethics review committee (DRERC), school of Allied health sciences, College of Health Sciences, Addis Ababa University (Ref.No: 132645/18). An informed consent was obtained from mother /guardian before collection of blood specimens and results were used in the management of patients. Written consent was sought for the study and any information related with the patient result and clinical history was kept confidential. 
Not applicable

\section{Availability of data and material}

The data is available in first author and can provide when necessary

\section{Competing interests}

We declare the is no competing interest

\section{Funding}

Not available

\section{Authors' contributions}

$\mathrm{MM}$, topic selection, designed the study protocol, participated in data collection, performed analysis, interpretation and wrote the research thesis, ZA, wrote the first and final draft of the manuscript for publication, $\mathrm{KD}$, advised and approved the research topic selection, provide the inputs during analysis and interpretation of the whole research paper. All authors read and approved the final manuscript.

\section{Acknowledgements}

We grateful thank to Medical Laboratory Sciences, school of Allied health sciences, College of Health Sciences, Addis Ababa University and Tikur Anbesa Specialized Hospital microbiology laboratory for their unpreserved support during the entire work.

\section{Authors' Information}

${ }^{1}$ Department of Microbiology Laboratory, Tikur Anbesa Specialized Hospital, Addis Ababa University, Ethiopia. ${ }^{2}$ Ethiopian public health institutes, Addis Ababa, Ethiopia. ${ }^{3}$ Departments of Microbiology and Parasitology, Addis Ababa University, Ethiopia.

\section{References}

1. Saeed M, Rasheed F, Ashraf F, Iram S, Hussain S, Khawaja AR. PATHOGENS CAUSING BLOOD STREAM INFECTIONS. The Professional Medical Journal. 2015; 22(12):1617-23.

2. Diekma DJ, Beekman SE, Chapin KC, Morel KA, Munson E, Deorn GV: Epidemiology and outcome of nosocomial and community onset bloodstream infection. J ClinMicrobio/ 2003, 41:3655-3660.

3. Aiken AM, Mturi N, Njuguna P, Mohammed S, Berkley JA, Mwangi I, Mwarumba S, Kitsao BS, Lowe BS, Morpeth SC, Hall AJ. Risk and causes of paediatric hospital-acquired bacteraemia in Kilifi District Hospital, Kenya: a prospective cohort study. The Lancet. 2011; 378(9808):2021-7.

4. Karunakaran R, Raja NS, Ng KP, Navaratnam P. Etiology of blood culture isolates among patients in a multidisciplinary teaching hospital in Kuala Lumpur. JOURNAL OF MICROBIOLOGY IMMUNOLOGY AND INFECTION. 2007; 40(5):432-7. 
5. Becker JU, Theodosis C, Jacob ST, Wira CR, Groce NE: Surviving sepsis in low-income and middle-income countries: new directions for care and esearch. Lancet Infect Dis. 2009, 9(Suppl 9):577-582.

6. Tziamabos AO, Kasper DL. Principle and practice of infectious diseases. Frank Polizano J. 2005; 26:2810-6.

7. Madsen $\mathrm{KH}$, Sorensen $\mathrm{HT}$ : Secular trends in incidence and mortality of bacteremia in Danish country. APMIS 1999, 107:346-352.

8. Zenebe T, Kannan S, Yilma D, Beyene G. Invasive bacterial pathogens and their antibiotic susceptibility patterns in Jimma University specialized Hospital, Jimma, and Southwest Ethiopia. Ethiopian journal of health sciences. $2011 ; 21(1): 1-8$.

9. Harbarth S, Ferrière K, Hugonnet S, Ricou B, Suter P, Pittet D: Epidemiology and prognostic determinants of bloodstream infections in surgical intensive care. Arch Surg. 2002, 137:1353-1359.

10. Ibrahim EH, Sherman G, Ward S: The influence of inadequate antimicrobial treatment of bloodstream infections on patient outcomes in the ICU setting. 2000, 118:146-155.

11. World Health Organization. Antimicrobial resistance: global report on surveillance. Geneva: World Health Organization. 2014.

12. Leistner R, Gürntke S, Sakellariou C, Denkel LA, Bloch A, Gastmeier P, Schwab F. Bloodstream infection due to extended-spectrum beta-lactamase (ESBL)-positive K. pneumoniae and E. coli: an analysis of the disease burden in a large cohort. Infection. 2014; 42(6):991-7.

13. Leistner R, Sakellariou C, Gurntke S, Kola A, Steinmetz I, Kohler C, et al. Mortality and molecular epidemiology associated with extended-spectrum beta-lactamase production in Escherichia coli from bloodstream infection. Infect Drug Resist. 2014; 7:57-62.

14. Willmann M, Kuebart I, Marschal M, Schroppel K, Vogel W, Flesch I, et al. Effect of metallo-beta-lactamase production and multidrug resistance on clinical outcomes in patients with Pseudomonas aeruginosa bloodstream infection: a retrospective cohort study. BMC Infect Dis. 2013; 13:515.

15. Vlieghe E, Phoba MF, Tamfun JJM, Jacobs J. Antibiotic resistance among bacterial pathogens in Central Africa: a review of the published literature between 1955 and 2008. Int J Antimicrob Agents. 2009; 34(4):295-303.

16. Ashley EA, Lubell Y, White NJ, Turner P. Antimicrobial susceptibility of bacterial isolates from community acquired infections in Sub-Saharan Africa and Asian low and middle income countries. Trop Med Int Health. 2011; 16(9):1167-1179.

17. Moss W. An outbreak of gentamicin-resistant Klebsiella bacteraemia at a children's hospital. Ethiopian medical journal. 1992; 30(4):197-205.

18. http://www.aau.edu.et/services/Hospital/background-of-college-of-health-sciences/

19. Negussie A, Mulugeta G, Bedru A, Ali I, Shimeles D, Lema T, Aseffa A. Bacteriological profile and antimicrobial susceptibility pattern of blood culture isolates among septicemia suspected children in selected hospitals Addis Ababa, Ethiopia. International journal of biological and medical research. 2015; 6(1):4709.

20. Thorpe TC, Wilson ML, Turner JE, DiGuiseppi JL, Willert M, Mirrett S, Reller LB. BacT/Alert: an automated colorimetric microbial detection system. Journal of clinical microbiology. 1990; 28(7):1608-12.

21. Wayne PA. Clinical and laboratories standards institute. Performance standards for antimicrobial susceptibility testing; 27th informational supplement. Clinical and laboratories standards institute CLSI 
document M100. 2017.

22. Slonim AD, Kurtines HC, Sprague BM, Singh N. The costs associated with nosocomial bloodstream infections in the pediatric intensive care unit. Pediatric Critical Care Medicine. 2001;2(2):170-4.

23. Abebaw A, Tesera H, Belachew T, Mihiretie GD. The bacterial profile and antibiotic susceptibility pattern among patients with suspected bloodstream infections, Gondar, north-west Ethiopia. Pathology and Laboratory Medicine International. 2018; 10:1-7.

24. El-Din S, Rabie EM, El-Sokkary MM, Bassiouny MR, Hassan R. Epidemiology of neonatal sepsis and implicated pathogens: a study from Egypt. BioMed research international. 2015; 1-11

25. Kayange N, Kamugisha E, Mwizamholya DL, Jeremiah S, Mshana SE. Predictors of positive blood culture and deaths among neonates with suspected neonatal sepsis in a tertiary Hospital, Mwanza-Tanzania. BMC pediatrics. 2010; 10(1):39.

26. Zakariya BP, Bhat V, Harish BN, Babu TA, Joseph NM. Neonatal sepsis in a tertiary care Hospital in South India: bacteriological profile and antibiotic sensitivity pattern. The Indian Journal of Pediatrics. 2011; 78(4):413-7.

27. Khanal B, Harish BN, Sethuraman KR, Srinivasan S. Infective endocarditis: report of a prospective study in an Indian Hospital. Tropical doctor. 2002; 32(2):83-5.

28. Seboxa T, Amogne W, Abebe W, Tsegaye T, Azazh A, HailuW,et al. High mortality from blood stream infection in Addis Ababa, Ethiopia, is due to antimicrobial resistance. PloS one. 2015; 10(12):e0144944.

29. Mahende C, Ngasala B, Lusingu J, Butichi A, Lushino P, LemngeM,et al. Bloodstream bacterial infection among outpatient children with acute febrile illness in north-eastern Tanzania. BMC research notes. 2015;8(1):1178-9.

30. Nielsen MV, Sarpong N, Krumkamp R, Dekker D, Loag W, Amemasor S, et al. Incidence and characteristics of bacteremia among children in rural Ghana. PloS one. 2012; 7(9):e44063.

31. Meremikwu MM, Nwachukwu CE, Asuquo AE, Okebe JU, Utsalo SJ. Bacterial isolates from blood cultures of children with suspected septicaemia in Calabar, Nigeria. BMC infectious diseases. 2005; 5(1):110.

32. Singh AK, Venkatesh V, Singh RP, Singh M. Bacterial and antimicrobial resistance profile of bloodstream infections: a Hospital-based study. CHRISMED Journal of Health and Research. 2014; 1(3):140.

33. Tariq TM. Bacteriologic profile and antibiogram of blood culture isolates from a children's hospital in Kabul. J Coll Physicians Surg Pak. 2014; 24(6):396-9.

34. Shrestha S, Amatya R, Shrestha RK, Shrestha R. Frequency of Blood Culture Isolates and their Antibiogram in a Teaching Hospital. J Nepal Med Assoc .2014; 52(193):692-7

35. Larru B, Gong W, Vendetti N, Sullivan KV, Localio R, Zaoutis TE, et al. Bloodstream infections in Hospitalized children: epidemiology and antimicrobial susceptibilities. The Pediatric infectious disease journal. 2016; 35(5):507-10.

36. Crichton H, O'Connell N, Rabie H, Whitelaw AC, Dramowski A. Neonatal and paediatric bloodstream infections: Pathogens, antimicrobial resistance patterns and prescribing practice at Khayelitsha District Hospital, Cape Town, South Africa. SAMJ: South African Medical Journal. 2018; 108(2):99-104.

37. Abrha A, Abdissa A, Beyene G, Getahun G, Girma T. Bacteraemia among severely malnourished children in Jimma university hospital, Ethiopia. Ethiopian journal of health sciences. 2011; 21(3):175-182. 
38. Talbert AW, Mwaniki M, Mwarumba S, Newton CR, Berkley JA. Invasive bacterial infections in neonates and young infants born outside Hospital admitted to a rural Hospital in Kenya. Pediatr Infect Dis J. 2010; 29(10):945-9.

39. Nielsen MV, Sarpong N, Krumkamp R, Dekker D, Loag W, Amemasor S, et al. Incidence and characteristics of bacteremia among children in rural Ghana. PLoS One. 2012; 7(9):e44063.

40. Akoua-Koffi C, Tia H, Plo JK, Monemo P, Cissé A, Yao C, et al. Epidemiology of community-onset bloodstream infections in Bouaké, central Côte d'Ivoire. New microbes and new infections. 2015; 7:100-4.

41. Kumar S, Rizvi M, Vidhani S, Sharma VK. Changing face of septicaemia and increasing drug resistance in blood isolates. Indian journal of pathology \& microbiology. 2004; 47(3):441-6.

42. Jyothi P, Basavaraj MC, Basavaraj PV. Bacteriological profile of neonatal septicemia and antibiotic susceptibility pattern of the isolates. Journal of natural science, biology, and medicine. 2013; 4(2):306-9.

43. Berezin EN, Solórzano F. Gram-negative infections in pediatric and neonatal intensive care units of Latin America. The Journal of Infection in Developing Countries. 2014; 8(08):942-53.

44. Kruse AY, ThieuChuong DH, Phuong CN, Duc T, Graff Stensballe L, Prag J, et al. Neonatal bloodstream infections in a pediatric Hospital in Vietnam: a cohort study. Journal of tropical pediatrics. 2013; 59 (6):4838.

45. Kante M, Lakshmi PM, Sreenivasulu Reddy PS. Bacterial profile of blood stream infections and their antibiograms. Int J Res Med Sci. 2015; 3(3):698-704.

46. Murni IK, Duke T, Kinney S. Antibiotic resistance and mortality in children with nosocomial bloodstream infection in a teaching hospital in Indonesia. Southeast Asian J Trop Med Public Health. 2016; 47:983-3.

47. Dagnew M,Yismaw G, Gizachew M, Gadisa A, TigistAbebe T, Tadesse T et al. Bacterial profile and antimicrobial susceptibility pattern in septicemia suspected patients attending Gondar University Hospital, Northwest Ethiopia. BMC Res Notes. 2013; 6: 283.

48. Acquah SE, QuayeL,Sagoe K, Ziem JB, Bromberger PI and Amponsem AA. Susceptibility of bacterial etiological agents to commonly-used antimicrobial agents in children with sepsis at the Tamale Teaching Hospital. BMC Infectious Diseases .2013; 13:89.

49. Zenebe T, Kannan S, Yilma D, Beyene G. Invasive bacterial pathogens and their antibiotic susceptibility patterns in Jimma University specialized Hospital, Jimma, and Southwest Ethiopia. Ethiopian journal of health sciences. 2011; 21(1):1-8.

50. Hailu D, Abera B, Yitayew G, Mekonnen D, Derbie A. Bacterial blood stream infections and antibiogram among febrile patients at Bahir Dar Regional Health Research Laboratory Center, Ethiopia. Ethiopian Journal of Science and Technology. 2016; 9(2):103-12.

51. Karki S, Rai GK, Manandhar R. Bacteriological analysis and antibiotic sensitivity pattern of blood culture isolates in Kanti children Hospital. Journal of Nepal Pediatric Society. 2010; 30(2):94-7.

52. Shrestha S, Amatya R, Shrestha RK, Shrestha R. Frequency of blood culture isolates and their antibiogram in a teaching Hospital. Journal of Nepal Medical Association. 2014; 52(193):692-7.

53. Pereira CA, Marra AR, Camargo LF, Pignatari AC, Sukiennik T, Behar PR., et al. Nosocomial bloodstream infections in Brazilian pediatric patients: microbiology, epidemiology, and clinical features. PloS one. 2013; 8(7):e68144. 
54. Zakariya BP, Bhat V, Harish BN, Babu TA, Joseph NM. Neonatal sepsis in a tertiary care Hospital in South India: bacteriological profile and antibiotic sensitivity pattern. The Indian Journal of Pediatrics. 2011; 78(4):413-7.

55. Gill MK, Sharma S. Bacteriological profile and antibiotic resistance pattern in blood stream infection in critical care units of a tertiary care Hospital in North India. Indian Journal of Microbiology Research. 2016; 3(3):270-4.

56. Mushi MF, Mshana SE, Imirzalioglu C, Bwanga F. Carbapenemase genes among multidrug resistant gram negative clinical isolates from a tertiary Hospital in Mwanza, Tanzania. BioMed research international. $2014 ; 1-6$.

57. Sangare SA, Maiga Al, Guindo I, Maiga A, Camara N, Dicko OA., et al. Prevalence of ESBL-producing Enterobacteriaceae isolated from blood cultures in Mali. The Journal of Infection in Developing Countries. 2016; 10(10):1059-64.

\section{Tables}

Table 1 : Distribution of socio-demographic and clinical condition of pediatric patients suspected of blood stream infection in Tikur Anbesa Specialized Hospital , 2018 


\begin{tabular}{|c|c|}
\hline Variables & Frequency (\%) \\
\hline \multicolumn{2}{|l|}{ Sex } \\
\hline Male & 122(35.9) \\
\hline Female & $218(64.1)$ \\
\hline \multicolumn{2}{|l|}{ Age group } \\
\hline Neonates (<28days) & $111(32.6)$ \\
\hline Infants (<1years) & 115(33.8) \\
\hline Children(<5years) & 114(33.5) \\
\hline \multicolumn{2}{|l|}{ Clinical condition } \\
\hline $\mathrm{CHF}$ & $29(8.5)$ \\
\hline Hospital acquired infection & $43(12.6)$ \\
\hline Early onset of neonatal sepsis & $71(20.8)$ \\
\hline Late onset of neonatal sepsis & $48(14.1)$ \\
\hline Sepsis & $102(30.0)$ \\
\hline Mengitidis & $3(0.8)$ \\
\hline Neuroblastoma & $5(1.5)$ \\
\hline Community acquired pneumonia & $7(2.0)$ \\
\hline Endocarditis & $11(3.2)$ \\
\hline Neutrophenic fever & $9(2.6)$ \\
\hline Othrs & 12(3.5) \\
\hline \multicolumn{2}{|l|}{ Unit of diagnosis } \\
\hline ICU & $83(24.4)$ \\
\hline Impatient & $181(53.2)$ \\
\hline Pediatric OPD & $76(22.4)$ \\
\hline \multicolumn{2}{|l|}{ Duration of admission } \\
\hline $1-2$ days & 61(17.9) \\
\hline 3-4 days & $76(22.4)$ \\
\hline 5-6 days & $41(12.0)$ \\
\hline$\geq 7$ days & $84(24.7$ \\
\hline \multicolumn{2}{|l|}{ Cause of high fever } \\
\hline Suspected bacteremia & $340(100)$ \\
\hline Malaria & $0(0)$ \\
\hline Others (viral, fungal...) & $0(0)$ \\
\hline \multicolumn{2}{|l|}{ Symptom of BSI } \\
\hline High grade Fever only & $267(78.5)$ \\
\hline Mild Fever and others & $73(21.5)$ \\
\hline \multicolumn{2}{|l|}{ Antibiotics taken before 07 days } \\
\hline Yes & $148(43.5)$ \\
\hline No & 192(56.5) \\
\hline \multicolumn{2}{|l|}{ History Hospital acquired infection } \\
\hline yes & $42(12.4)$ \\
\hline No & $298(87.6)$ \\
\hline \multicolumn{2}{|l|}{ Complication of BSI } \\
\hline Yes & $92(27.0)$ \\
\hline No & $248(73.0)$ \\
\hline
\end{tabular}

Table 2: Antimicrobial susceptibility of gram negative bacterial isolates associated with blood stream infection among pediatric patients in Tikur Anbesa Specialized Hospital, 2018 


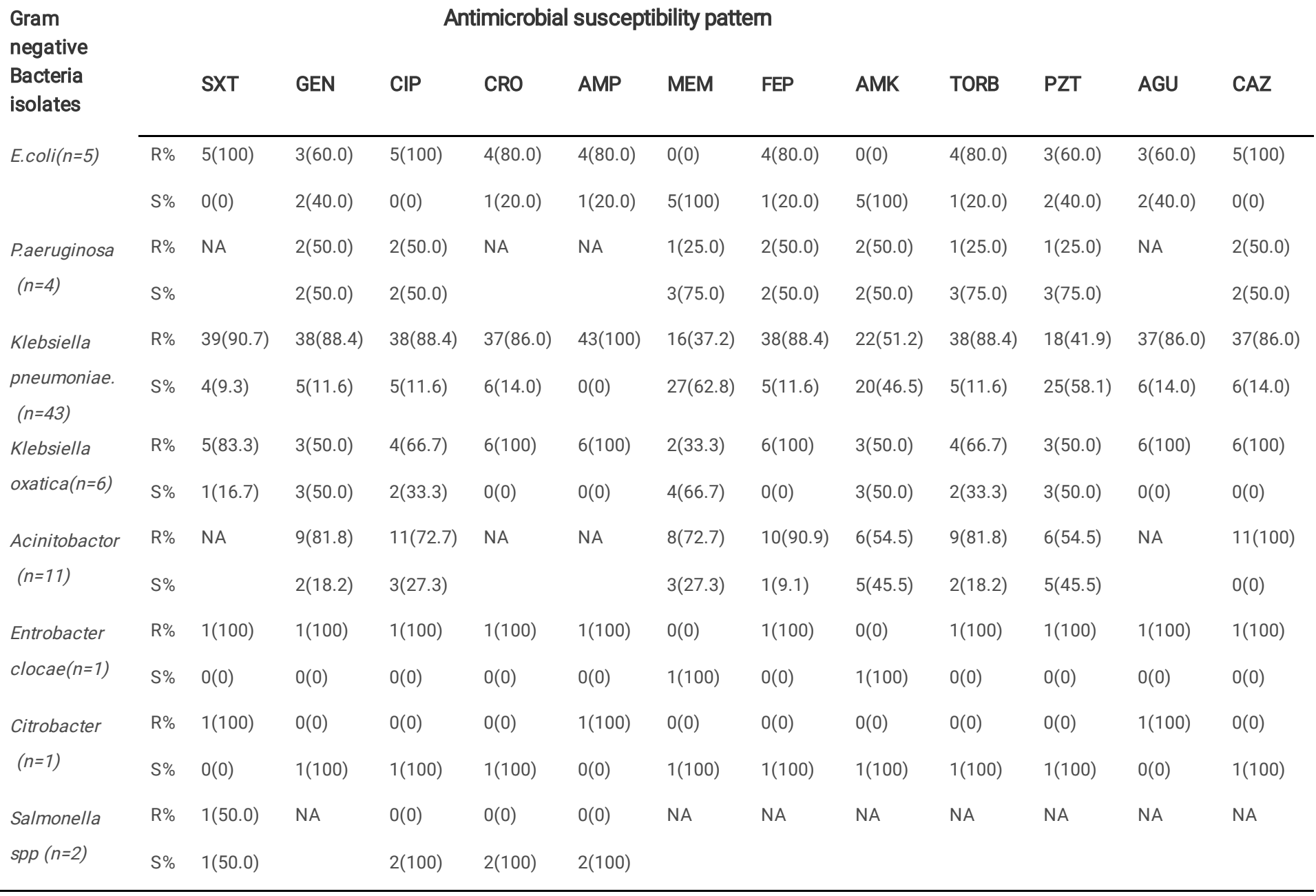

SXT-Sulphamethoxazol-trimethoperem/cotrimosazole, GN-Gentamycin, CIP-Ciprofloxacillin, CRO-ceftriaxone, AMP-ampicillin, MEM-Meropenem, FEP-Cefepime, AMK -Amikacin, CAZ- ceftazidime, Torbomycin, Piperacillin-Tazobactam, AGUAugmentin/Amoxycillin-Clavulanic acid, NA- Not applicable

Table 3: Resistance antibiogram of gram negative isolates from BSI among pediatric patients in Tikur Anbesa Specialized Hospital, 2018 


\begin{tabular}{|c|c|c|c|c|c|c|c|c|c|}
\hline \multirow[b]{2}{*}{ Bacterial isolates } & \multicolumn{9}{|c|}{ Resistance antibiogram } \\
\hline & RO\% & R1\% & R2\% & R3\% & R4\% & R5\% & R6\% & R7\% & $\geq \mathrm{R} 8 \%$ \\
\hline E.coli $(n=5)$ & $1(20)$ & - & $1(20)$ & 1(20) & $1(20)$ & - & 1(20) & - & - \\
\hline Pseudomonas $(n=4)$ & $2(50)$ & - & - & $2(50)$ & - & - & - & - & - \\
\hline $\begin{array}{l}\text { Klebsiella pneumoniae. } \\
(n=43)\end{array}$ & - & - & $1(2.3)$ & 2(4.6) & $1(2.3)$ & - & $2(4.6)$ & $2(4.6)$ & $35(81.4)$ \\
\hline Klebsiella oxytoca $(n=6)$ & - & - & 1(16.7) & - & - & 1(16.7) & 1(16.7) & - & $3(50)$ \\
\hline Acinitobactor $(n=11)$ & $3(27.3)$ & - & - & - & - & - & - & $1(9.1)$ & 7(63.6 \\
\hline $\begin{array}{l}\text { Entrobacter } \\
\text { clocae }(n=1)\end{array}$ & - & - & - & - & - & - & - & - & $1(100)$ \\
\hline Citrobacter $(n=1)$ & - & - & 1(100) & - & - & - & - & - & - \\
\hline Salmonella spp $(n=3)$ & $2(66.7)$ & $1(33.3)$ & - & - & - & - & - & - & - \\
\hline
\end{tabular}

$\mathrm{RO}, \mathrm{R} 1, \mathrm{R} 2, \mathrm{R} 3, \mathrm{R} 4, \mathrm{R} 5, \mathrm{R} 6, \mathrm{R} 7, \mathrm{R} 8, \mathrm{R} 9, \mathrm{R} 10$ sensitive, resistance to $1,2,3,4,5,6,7,8,9,10$ antibiotics respectively

\section{Figures}

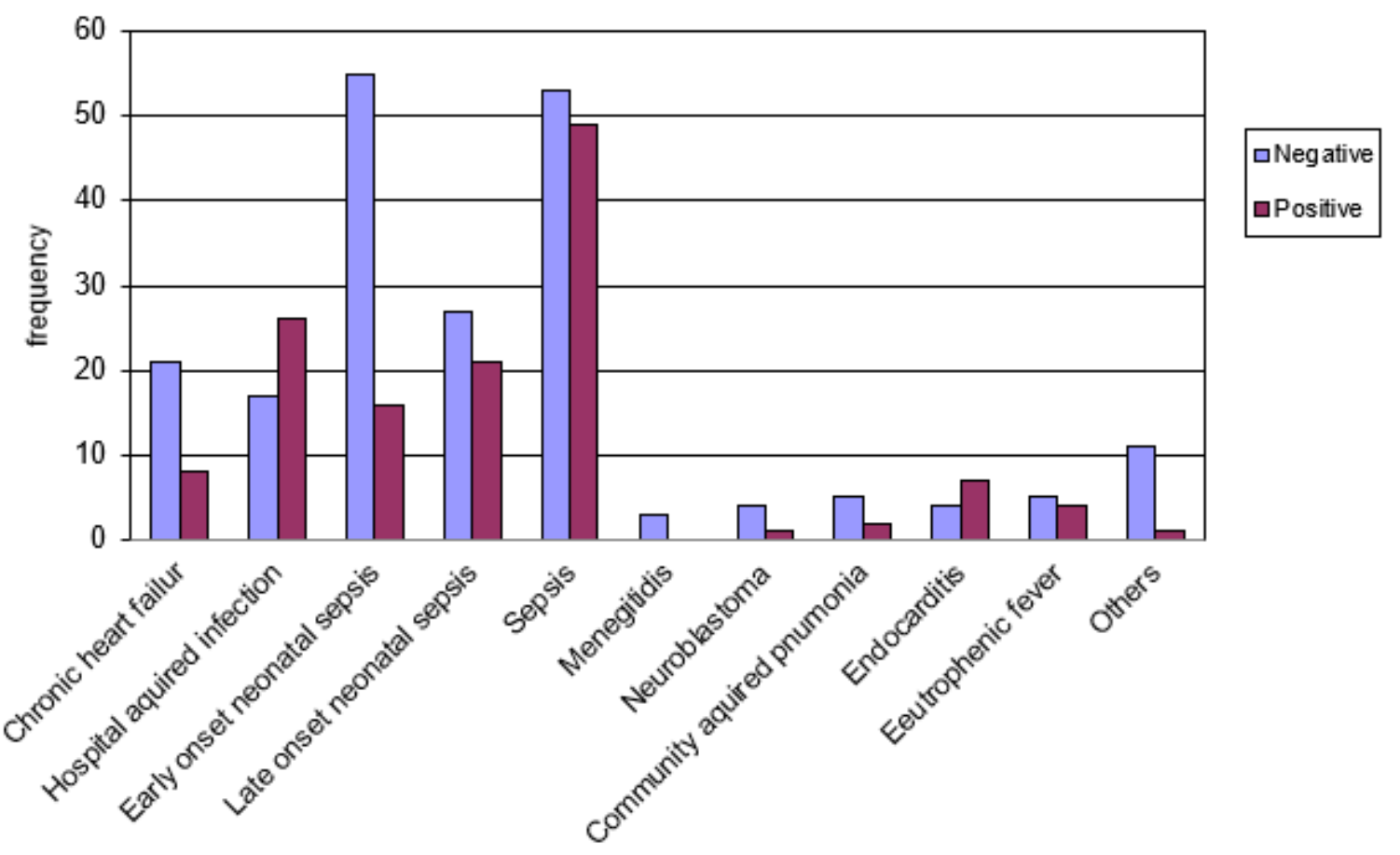

Figure 1

positive blood culture among clinical features:Distribution of clinical condition of patients among positive blood culture from blood stream infection suspected septicemia in Tikur Anbesa Specialized Hospital, 2018 


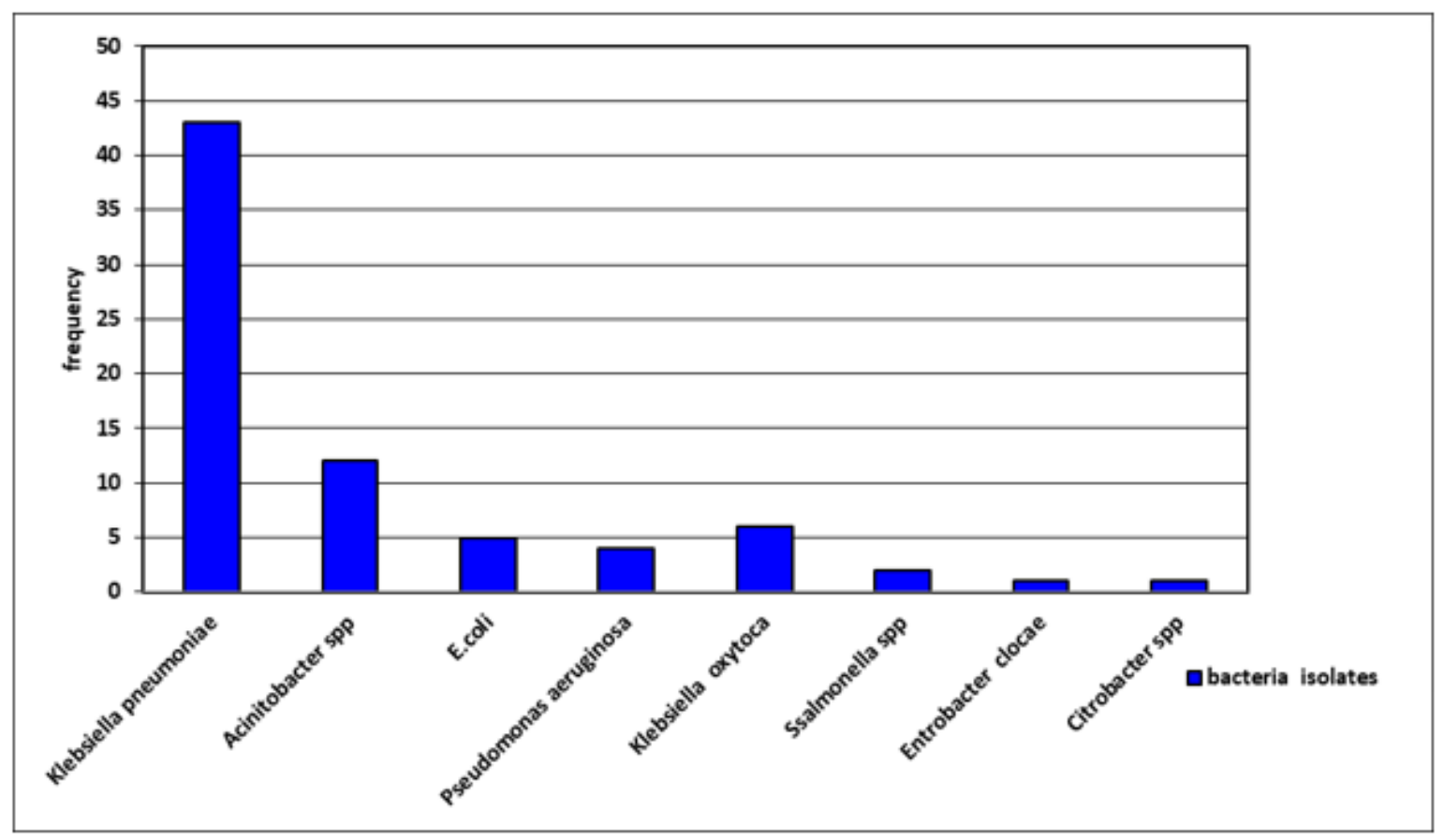

Figure 2

bacteria distribution among positive blood culture: Distribution of bacteria pathogens among positive blood culture isolated from blood stream infection suspected of septicemia patients in Tikur Anbesa Specialized Hospital, 2018 